\title{
Pulmonary inflammatory myofibroblastic tumour misdiagnosed as a round pneumonia
}

\author{
Samira Naime, ${ }^{1}$ Anjum Bandarkar, ${ }^{2}$ Gustavo Nino, ${ }^{3}$ Geovanny Perez ${ }^{4}$
}

${ }^{1}$ Pediatric Pulmonary and Sleep Medicine, Children's National Health System, Washington, DC, USA

${ }^{2}$ Radiology, Mid-Atlantic Permanente Medical Group, Reston, Virginia, USA

${ }^{3}$ Pediatric Pulmonary and Sleep Medicine, Children's National Health System, Washington, DC, USA

${ }^{4}$ Pediatric Pulmonary and Sleep Medicine, Children's National Health System, Washington, DC, USA

Correspondence to Dr Samira Naime, samira.naime@gmail.com

Accepted 2 February 2018

\section{DESCRIPTION}

A 9-year-old male patient, previously healthy, presented with acute-onset chest pain. The pain was on the right lateral chest, 10/10 in severity and non-reproducible. The patient had 1-week history of cough that had been improving; no fever, weight loss, dyspnoea, palpitations or night sweats were reported. He had positive sick contacts. Examination was remarkable for slight decrease in breath sounds at the right lower lung field posteriorly. Initial chest radiograph showed a well-circumscribed opacity in the right lower lobe posteriorly with adjacent consolidation seen on the lateral view. The lesion appeared to be distinct from the cardiomediastinal silhouette (figure 1). Sonography was performed to characterise the nature of the lesion; however, it was difficult to visualise and only revealed mixed echotexture (figure 2). Contrast-enhanced CT scan of the thorax was then obtained. CT showed a right posterior basal segment consolidation with hypo-enhancing components and rounded margins, most characteristic of round pneumonia. There was reactive thickening in the adjacent pleura without pleural effusion or pneumothorax. Few right hilar nodes were noted and thought to be reactive lymph nodes (figure 3 ).

A complete blood count with differential showed mild leukocytosis (white blood cell: $14 \mathrm{~K} / \mathrm{mcL}$ ) with left shift (neutrophils: 86\%), mild thrombocytosis (platelets of $490 \mathrm{~K} / \mathrm{mcL}$ ) and normocytic anaemia (Hemoglobin (Hg): $11.7 \mathrm{~g} / \mathrm{dL}$, Hematocrit (Hct): $36.2 \%$, mean corpuscular volume $(\mathrm{MCV})$ : $81 \mathrm{fL})$. Given the diagnosis of round pneumonia, the patient was started on intravenous ceftriaxone $2000 \mathrm{mg}$ /day for 2 days then switched to oral cefdinir to complete a course of 14 days of antibiotics. Repeat chest radiograph -8 weeks later-did not show significant changes, indicating a possible pulmonary tumour. Spirometry done at

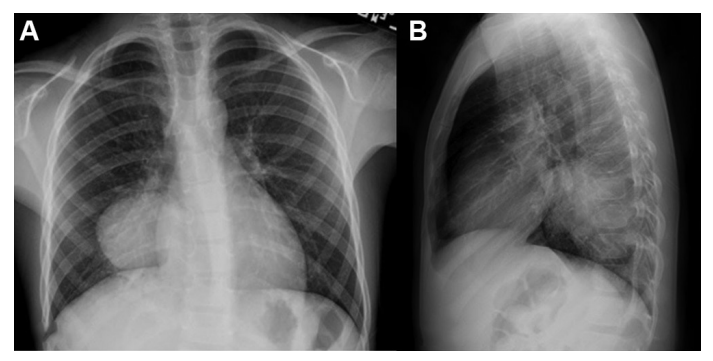

Figure 1 (A) Frontal and (B) lateral chest radiographs showing a rounded well-circumscribed opacity in the right lower lobe posteriorly measuring around $5 \mathrm{~cm}$ in diameter.

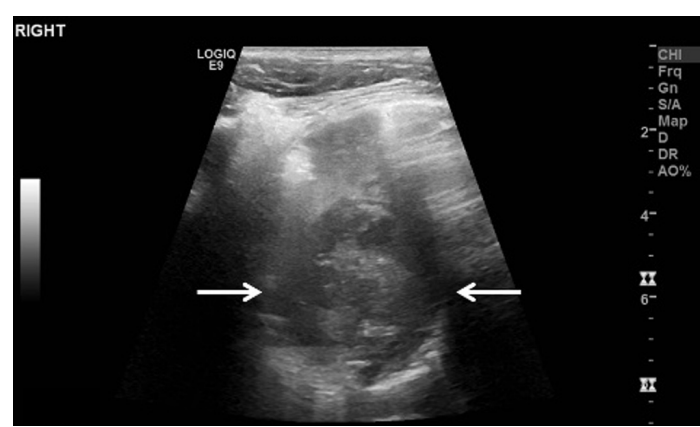

Figure 2 Grayscale sonography of the right lower chest from posterior approach, showing a rounded area of heterogeneously mixed echotexture (arrows) with surrounding sonographic air bronchograms.

that visit was normal, indicating that the mass was in the parenchyma and less likely compressing the airways. Contrast-enhanced MRI of the chest was obtained to delineate the mass and rule out spinal cord invasion. MRI showed a heterogeneously enhancing mass in the right lower lobe with some internal necrosis (figure 4). The patient was referred to paediatric surgery, and right lower lobectomy with complete excision of the mass was performed. Pathology showed inflammatory myofibroblastic tumour (IMT) with anaplastic lymphoma kinase (ALK) positive. The postoperative course was unremarkable, and the patient remained asymptomatic on postoperative days 7 and 14. Repeat chest radiograph showed resolution of pleural fluid and pneumomediastinum that was present during the immediate postoperative films.

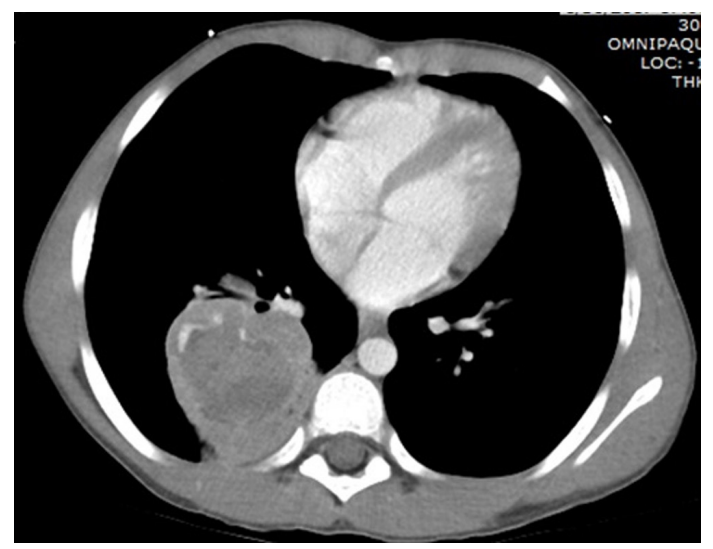

Figure 3 Contrast-enhanced CT scan of the chest showing a well-defined round mass with patchy enhancement and adjacent compressive atelectasis; the findings favour the diagnosis of round pneumonia. 

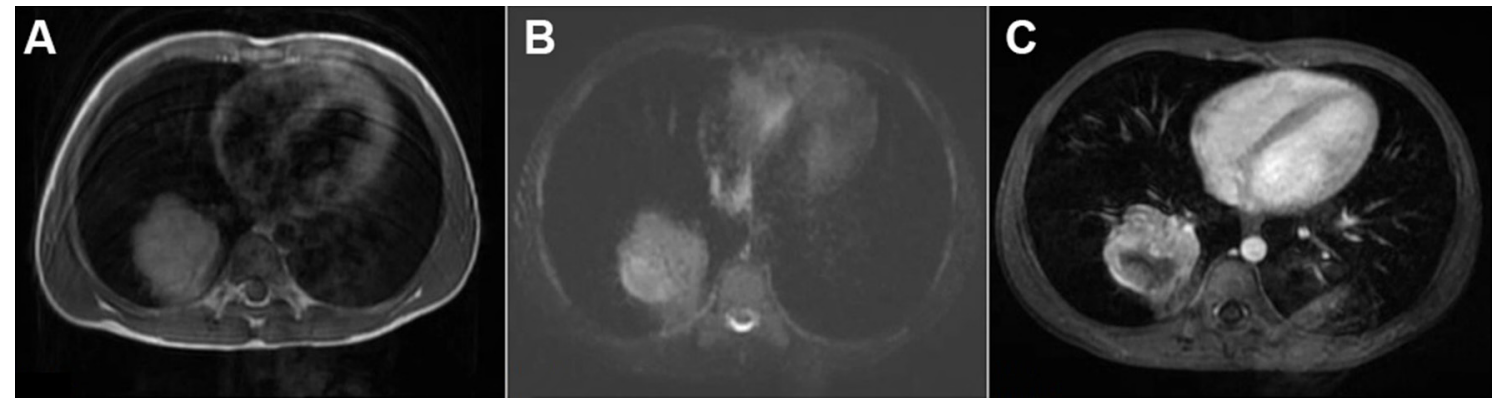

Figure 4 Axial (A) unenhanced T1-weighted, (B) T2-weighted and (C) contrast-enhanced T1-weighted MRI shows a heterogeneously enhancing mass in the right lower lobe with areas of necrosis.

Inflammatory myofibroblastic tumour is the most common benign paediatric pulmonary tumour, constituting $50 \%$ of all benign tumours. ${ }^{1}$ Aetiology is not known, prior viral infections and trauma have been proposed but not proven. It has been reported to recur locally in up to $24 \%$ of patients. Most IMT stain positive for ALK. Radiological findings are not specific; it can be a peripheral lesion in lower lobes or a hilar lesion. It can have heterogeneous density on CT scan and calcifications may be seen. ${ }^{2}$ The treatment remains complete surgical resection. Some adjunct therapies such as non-steroidal anti-inflammatory drugs, steroids and chemotherapy have been used; however, efficacy of those treatments is not well documented. ${ }^{3}$

\section{Learning points}

Inflammatory myofibroblastic tumour is the most common paediatric pulmonary benign tumour.

- Non-specific radiological findings cannot be easily distinguished from malignant tumour.

- Treatment of choice is complete surgical resection.
Contributors $S N$ wrote the manuscript. $A B$ edited and commented on the images in the report. GN and GP contributed to the critical revision of the manuscript.

Competing interests None declared.

Patient consent Obtained.

Provenance and peer review Not commissioned; externally peer reviewed.

(C) BMJ Publishing Group Ltd (unless otherwise stated in the text of the article) 2018. All rights reserved. No commercial use is permitted unless otherwise expressly granted.

\section{REFERENCES}

1 Weldon CB, Shamberger RC. Pediatric pulmonary tumors: primary and metastatic. Semin Pediatr Surg 2008;17:17-29.

2 Ufuk F, Herek D, Karabulut N. Inflammatory myofibroblastic tumor of the lung: unusual imaging findings of three cases. Pol J Radiol 2015;80:479-82.

3. Telugu RB, Prabhu AJ, Kalappurayil NB, et al. Clinicopathological Study of 18 Cases of Inflammatory Myofibroblastic Tumors with Reference to ALK-1 Expression: 5-Year Experience in a Tertiary Care Center. J Pathol Trans/ Med 2017;51:255-63.

Copyright 2018 BMJ Publishing Group. All rights reserved. For permission to reuse any of this content visit

http://group.bmj.com/group/rights-licensing/permissions.

BMJ Case Report Fellows may re-use this article for personal use and teaching without any further permission.

Become a Fellow of BMJ Case Reports today and you can:

- Submit as many cases as you like

- Enjoy fast sympathetic peer review and rapid publication of accepted articles

- Access all the published articles

Re-use any of the published material for personal use and teaching without further permission

For information on Institutional Fellowships contact consortiasales@bmjgroup.com

Visit casereports.bmj.com for more articles like this and to become a Fellow 